\title{
A REVIEW: LITERATURE ON POTHOLE MONITORING SYSTEM
}

\author{
Sneha Gosavi \\ BE student \\ VIT, Mumbai \\ Nisha Pandav \\ BE student \\ VIT, Mumbai
}

\author{
Joshna Chinta \\ BE student \\ VIT, Mumbai \\ Asst. Prof. Kanchan Dhuri
Assistant professor
VIT, Mumbai
}

Abstract - In today's life transportation is one of the most important part of human's life. That is why road surface quality becomes major issue as many of the accidents takes place because of bad condition of roads. The optimal solution for road repairs can be provided by collecting multiple amount of real time data about the state of the roads and this data can be achieved by participation and interaction of people. Several methods have been implemented to overcome this problem. Several proposed methods require dedicated hardware for implementation of system such as GPS devices and accelerometers in vehicles or cameras on roadside and near traffic signals for collection of data. All such methods are expensive in terms of monetary cost and more human power is required. Instead of using such expensive devices we can use some sensors which are already present in our smart phones. A simple smart phone can be used for detecting potholes on the roads and which can be used by anyone. Our main motive is to reduce the human efforts for detecting a pothole using a simple, easily usable and cost-efficient way and which result into reduction of accidents that cause due to potholes.

Key Words: Pothole, Authorities, Acceleration, Android, Sensors

\section{INTRODUCTION}

Bad road conditions are big problem for safe and comfortable transportation However, this condition is supposed to be find out first. First approach towards detection of road damage is human report by themselves to central authorities. While that process has the highest accuracy assuming that people are fair, it also requires the most human participation. Statistical analysis can be used to find out approximate damage probabilities of road segments based on their usage intensity. For the same purpose new road monitoring method called surface analysis is developed which uses different hardware like Ground Penetrating Radar (GPR) etc. and its commercial products are also exist. Unfortunately, the equipment's which are required for above method are very expensive therefore limits its accessibility. As an alternative, participatory sensing has the potential to increase the collected data resolution and scope.

The simplest method might be to click the photos of road damage such as potholes by the people and to send them to a respected authority. However, this requires strong participation and interaction from the users as well as manual image analysis. As it requires more human interaction it can be more human resource consuming as well as time consuming. To make this process less power and time consuming, an automated approach for detecting potholes with little or no human interaction is more promising. This would help to collect more accurate real time data with less errors caused by human factors than generated by participation of the people. To create properly working pothole monitoring system accepted by wide user community, it is important to make it more attractive, Interactive and user-friendly so that user can access it very efficiently.

\section{PROPOSED SYSTEM}

This system works or is divided into different modules. The different steps can be shown using a flowchart. Flowchart can be formed as follows: - 


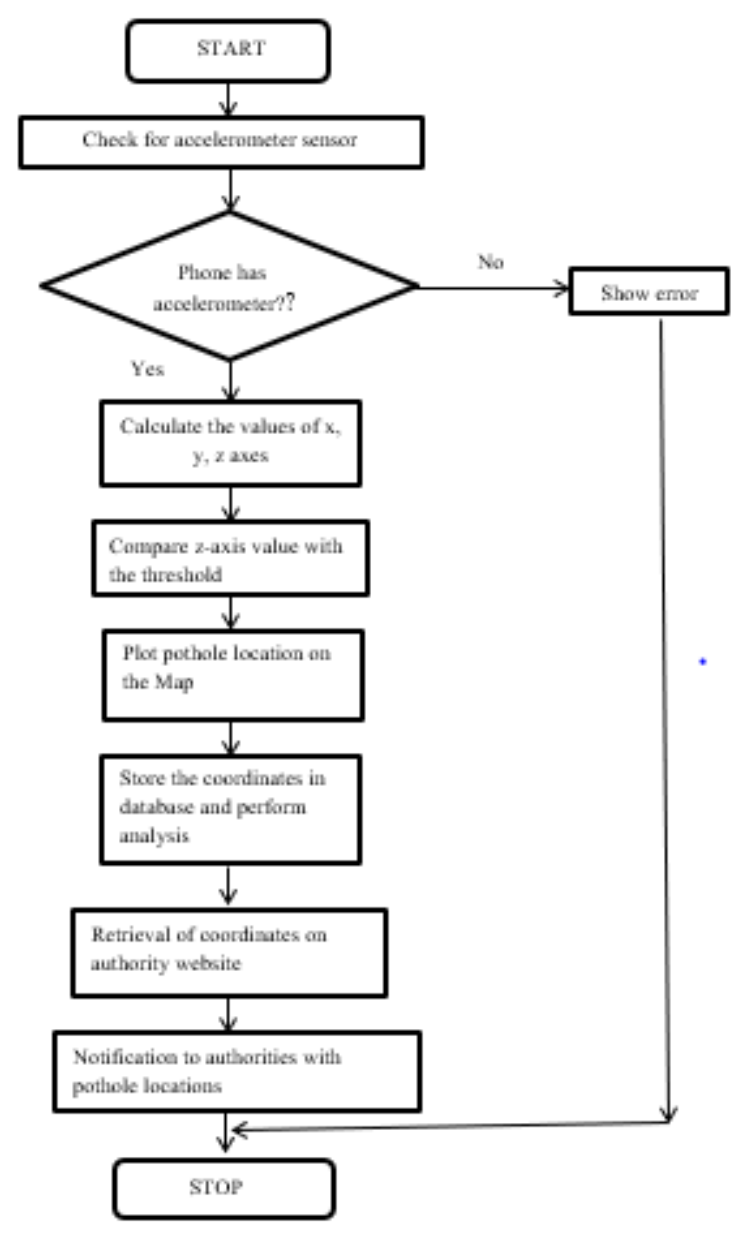

Fig1.Proposed System Flowchart

In this app we read data from the accelerometer sensor and detect when the phone has been shaken and detection of potholes on the road:

1. The first thing to do is check whether the phone has an accelerometer in the first place. If not, you can notify your user.

2. Alternatively, if your user must have an accelerometer to use your app properly you can notify the user and then close the app. This project retrieves the values of the $\mathrm{x}, \mathrm{y}$, and $\mathrm{z}$ axis from the accelerometer sensor. It also indicates when the device has been shaken. If your Android device is laid face up on a table top, the ZAccel value from gravity will be positive. Turning the device on its left side will make the XAccel value positive Standing the device upright will give YAccel a positive value. Gravity $(9.81 \mathrm{~m} / \mathrm{s} / \mathrm{s})$ and we can view this with an Android app. If the accelerometer value changes the shaking function is called. And instantly the coordinates will be taken through GPS where the jerk took place by calculating longitude and latitude of the specific position where the event occurred.
The coordinates will be located and will be entered into database containing exact shaking positions where the potholes are present.

\section{EXPERIMENT AND RESULT}

In implemented system we have two main phases first is actual application and second one is website which is specifically for Admin use.

We created an application for user in which we included 3 screens as below:

1. Acceleration sensing screen

2. Map screen

3. Acknowledgement screen

In acceleration screen we are retrieving GPS coordinates and accelerometer data from sensors which are already present in android smartphones and displaying it on screen. In Map screen map is displayed with pins which points the pothole using retrieved GPS coordinates as per set threshold values. To get more accurate locations we are doing analysis using $\mathrm{K}$ means clustering which gives approximate location coordinates by analyzing all co-ordinate values in acknowledgement screen user has to subscribe to acknowledgement topic and generate token so that user is able to get acknowledgement/notification send by admin of respected application. In website admin gets analysed data which admin can enter into location finder page which gives location by processing entered data which is longitude and latitude points. Then location is sent to the respected authorities as per areas from website.

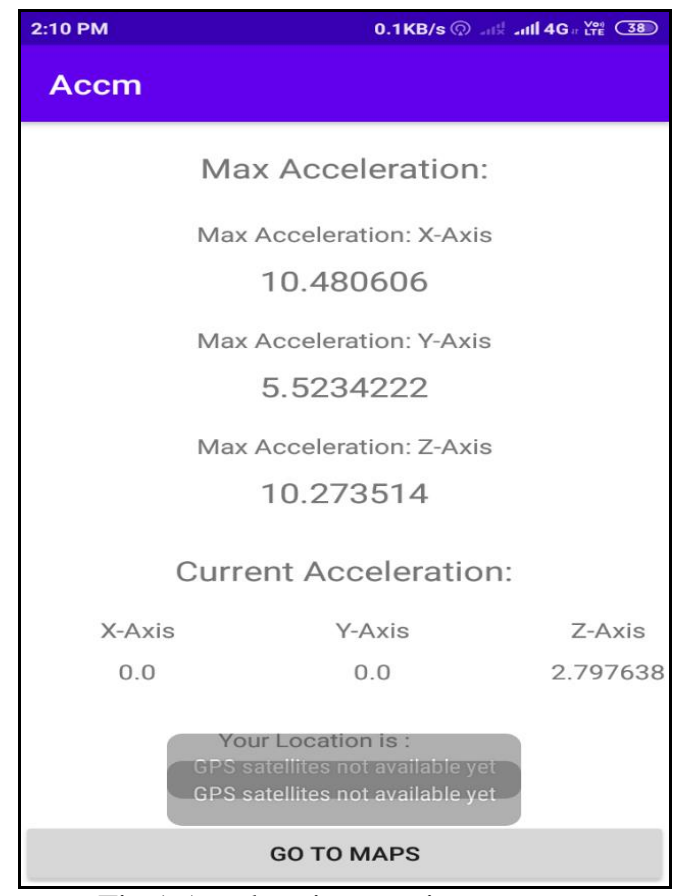

Fig.1 Acceleration sensing screen 


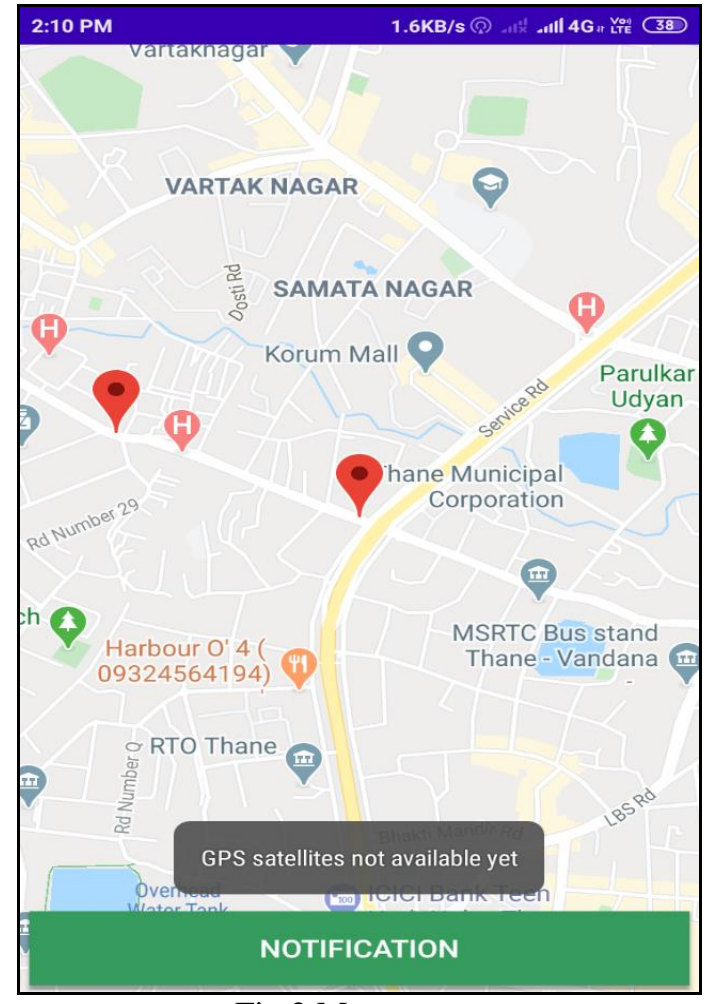

Fig.2 Map screen

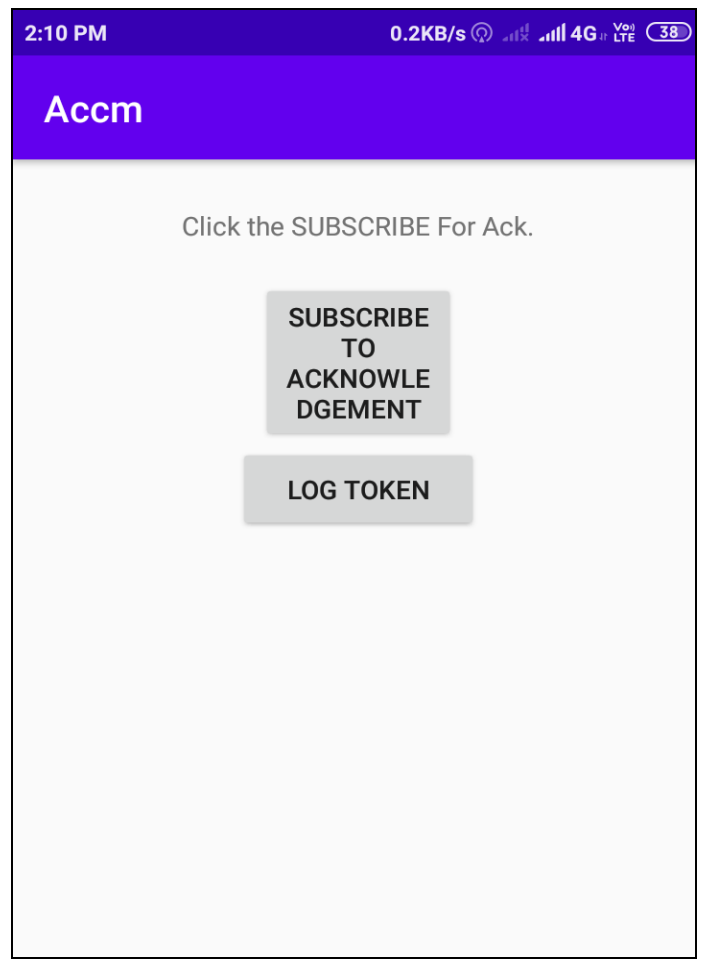

Fig3. Acknowledgement screen

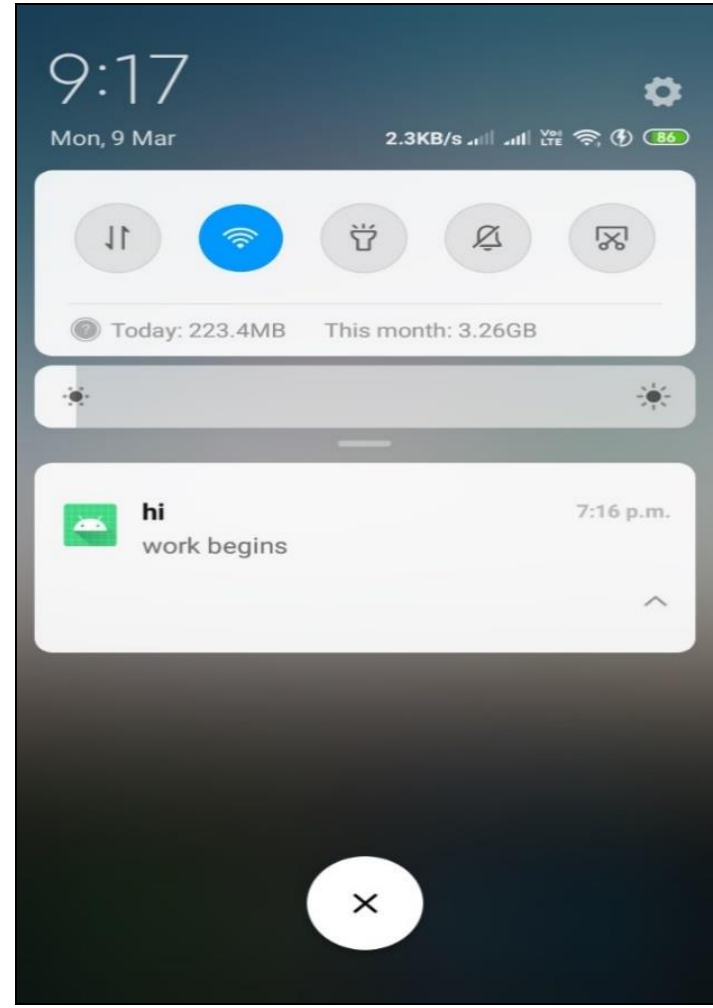

Fig4. Notification

\section{CONCLUSION}

From the above analysis we can conclude that implementation of this system will help Municipal authorities to take quick action against the potholes whose location will be detected using the created application and will result into minimizing the rate of road accidents compared to the current rate.

Currently we are using Z-DIFF and Z-THRESH algorithms for pothole detection and K-Means clustering algorithm for analysis of gathered data. In future we can add other algorithms which helps to add more accuracy in current project.

\section{REFERENCE}

[1]. Artis Mednis, Girts Strazdins, Reinholds Zviedris, Georgijs Kanonirs, Leo Selavo, "Real time pothole detection using android with accelerometer". 2011 7th IEEE International Conference on Distributed Computing in Sensor Systems and Workshops (DCOSS).

[2]. Victor Akinwande, Kayode Adewole, Olayiwola Bello, Abimbola Akintola, "Automatic and real-time pothole detections." International Conference on Computer Science Research and Innovations (CoSRI 2015), At University of Ibadan, Nigeria, August 2015. 
[3]. Bhoraskar R., Vankadhara N., Raman B. and Kulkarni P. (2012) Wolverine: Traffic and Road Condition Estimation Using Smartphone Sensors. 2012 Fourth International Conference on Communication Systems and Networks (COMSNETS), Bangalore, 3-7 January 2012.

[4]. Chugh, G., Bansal D., \& Sofat S., "Road Condition Detection Using Smartphone Sensors." International Journal of Electronic and Electrical Engineering. ISSN 0974-2174, Volume 7, Number 6 (2014), pp. 595-602 (C) International Research Publication House.

[5]. Chen K., Lu M., Fan X., Wei M., \& Wu J., (2011, August), "Road condition monitoring using on-board Threeaxis Accelerometer and GPS." Conference: Proceedings of the 2011 6th International ICST Conference on Communications and Networking in China, CHINACOM 2011. 